\title{
Tolerance of Water in Microfluidic Radiofluorinations: A Potential Methodological Shift?
}

\author{
Giancarlo Pascali $^{1,2 *}$, Mariarosaria De Simone ${ }^{1}$, Lidia Matesic ${ }^{2}$, Ivan Greguric ${ }^{2}$ and Piero A. Salvadori ${ }^{1}$ \\ ${ }^{1}$ Institute of Clinical Physiology, CNR, Via Moruzzi 1, 56124, Pisa, Italy \\ ${ }^{2}$ LifeSciences, Australian Nuclear Science and Technology Organisation, New Illawarra Road, Lucas Heights NSW 2234, Australia
}

Received: 1 December 2013; accepted: 21 February 2014

\begin{abstract}
Nucleophilic $\left[{ }^{18} \mathrm{~F}\right]$-fluorination reactions traditionally include a drying step of the labeling agent in order to achieve a successful substitution. This passage extends the time and complexity required for the whole radiotracer production, with increased hardware and detrimental effects on the radioactive recovery of such a short-lived $\left(t_{1 / 2}=109 \mathrm{~min}\right)$ isotope. Because the performance of radiofluorination reactions conducted under microfluidic flow conditions have been demonstrated to be more effective in terms of reaction time and yields, we have tested the tolerance to water present in this specific reaction condition, in view of eliminating the drying step in the process. To this purpose, we tested different substrates selected from typical radiofluorination intermediates. Our results show that water could be tolerated in a microfluidic environment; in particular, we observed a slight decrease in the labeling of aromatic precursors and a significant increase for iodonium salts, whereas the radiochemical yields of the other compounds studied were virtually unchanged. These findings may open the way to the possibility of simpler and faster processes for the production of new ${ }^{18} \mathrm{~F}$-fluorinated positron emission tomography tracers.
\end{abstract}

Keywords: microfluidics, radiochemistry, radiofluorination, PET, anhydrous, water

\section{Introduction}

$\left[{ }^{18} \mathrm{~F}\right]$-Radiofluorination is a key point in the synthetic routes leading to the preparation of positron emission tomography (PET) radiotracers because this step enables the incorporation of the desired radioactive label into the molecular context of interest. This reaction is delicate and difficult, primarily because of the paucity of labeled starting material [1], which calls for the best possible incorporation yield in order to not waste radioactive ${ }^{18} \mathrm{~F}$-fluoride, and must be conducted rapidly to cope with its short half-life (109 $\mathrm{min})$. The most frequently used route to radiofluorinated compounds makes use of the nucleophilic reaction, which employs high-specific radioactivity ${ }^{18} \mathrm{~F}$-fluoride reacted with suitable precursors [2]. However, the aqueous ${ }^{18} \mathrm{~F}$-fluoride solution produced at a cyclotron by proton bombardment of $\left[{ }^{18} \mathrm{O}\right]-\mathrm{H}_{2} \mathrm{O}$ requires the recovery of such anion from water and its extensive drying. The fluoride is usually converted to the potassium or cesium salt and finally dissolved into an appropriate organic solvent, often by means of phase transfer catalysts, such as tetrabutylammonium hydroxide (TBA) or potassium-kryptates $\left(\mathrm{K}_{222} / \mathrm{K}_{2} \mathrm{CO}_{3}\right)$ to enhance its nucleophilicity. A proper drying typically requires multiple additions of acetonitrile to the aqueous solution followed by evaporation of the acetonitrile/water azeotrope; this operation is regarded as a necessary step to be performed before the radiofluorination reaction. The implementation of this step includes the use of additional hardware and heating/cooling processes, which potentially lead to radioactive reagent losses, and the time employed (15-20 min) decreases the available amount of labeling agent due to radioactive decay. Therefore, several groups have investigated alternative ways to chemically activate fluoride. To this purpose, procedures employing ionic liquids [3], bulky tertiary alcohols [4], long-chain alkyl quaternary ammoniums, phosphoniums [5], and electrochemical cells [6] have been proposed. In the majority of these methods, a modified (and generally fast) trap/release approach is used, in which the released solution does not require a further workup to be successfully used in the radiolabeling step. However, the direct use of irradiated target $\left[{ }^{18} \mathrm{O}\right]-\mathrm{H}_{2} \mathrm{O}$ was only published with the

* Author for correspondence: giancarlo.pascali@ansto.gov.au use of ionic liquids [3], even if this method has not been used in successive reports.

Scattered data can be found throughout the literature regarding the tolerance of small percentages of water in the fluorination reaction mixture, employing a traditional $\mathrm{K}_{222} / \mathrm{K}_{2} \mathrm{CO}_{3}$ or TBA approach [7]. In general, it has been observed that the level of dryness required for optimal incorporation might not be necessarily high, as verified by our group in preliminary experiments [8]. The extent of this effect depends on the nature of the precursor to be radiolabeled and the hardware used.

However, no such data are reported on microfluidic approaches to radiotracer synthesis, which are increasingly used in the field and have been demonstrated to have great potential in achieving higher performances in radiofluorination reactions [9].

Therefore, the aim of this work is to employ a microfluidic flow system to evaluate incorporation yields on a selected set of model and real precursors while varying the water content and its additional method. The data collected will be compared to the results obtained in similar microfluidic conditions, utilizing standard azeotropic drying of the fluoride anion.

\section{Experimental}

2.1. General. All chemicals and solvents were purchased from Sigma-Aldrich or ABX (Germany) and used without further purification. The high-purity grade solvents were vented through a soda lime/molecular sieves trap upon use. Micro-SPE cartridges (MP-1) were purchased from ORTG (USA). Ditosylate precursors were synthesized according to published procedures [10]. 7-Chloronaphthyridines and aryliodonium salts were prepared at the Institute of Pharmacological Science at the University of Pisa, and the synthetic details will be published elsewhere. $\left[{ }^{18} \mathrm{~F}\right]$-fluoride was produced on a PETtrace cyclotron (GE Healthcare, USA) by proton bombardment $(\mathrm{Ep}=16.7 \mathrm{MeV}, 5-15 \mathrm{~min}$ at 20-25 $\mu \mathrm{A})$ of a $1.3-\mathrm{mL}^{18} \mathrm{O}$-water (enrichment $>98 \%$ ) in a silver target. The starting batch of activity was 2-5 GBq. Radio-HPLCs were obtained using a Delta 600 pump system (Waters, USA) equipped with a Gabi Star flow-through gamma detector (Raytest, Germany) connected in series to a 996 Photo Diode Array (PDA) UV detector (Waters, USA). A Phenomenex Synergi Fusion-RP $\mathrm{C}$-18 HPLC column $(4 \mu \mathrm{m}, 3 \times 150 \mathrm{~mm})$ was used with varying 
$\mathrm{CH}_{3} \mathrm{CN} / \mathrm{H}_{2} \mathrm{O}$ ratios. Thin Layer Chromatography (TLC) analyses were performed using silica plates and $100 \%$ EtOAc as eluent. Radio-TLCs were acquired using Cyclone PLUS (Perkin-Elmer, USA). Incorporation yield was calculated as the percentage of the radioactive product from the overall activity present at the end of each experiment $\left(\operatorname{Rad}_{\text {prod }} / \operatorname{Rad}_{\text {tot }}\right)$.

A general purpose NanoTek microfluidic system (Advion Inc., USA) was used to perform the labeling reactions, employing the traditional 1-step Automatic Discovery setup described in literature [11]; a Back Pressure Regulator (BPR) was used when $\mathrm{CH}_{3} \mathrm{CN}$ was selected as the solvent and was adjusted by leveling the pressure reading at 250 psi when pure $\mathrm{CH}_{3} \mathrm{CN}$ was flowing at $100 \mu \mathrm{L} / \mathrm{min}$ and $90{ }^{\circ} \mathrm{C}$. The microreactor employed was a $2 \mathrm{~m} \times 100 \mu \mathrm{m}$ I.D. (360 um O.D.) fused silica coil, featuring a $15.6-\mu \mathrm{m}$ internal volume.

2.2. Test Labeling Methods for Model Compounds. The different methods were obtained by varying the composition of the respective (precursor and labeling solution) storage loops. The concentrations of precursor were typically constant: 1-OTs, 2-OTs, and 3-OTs $=20 \mathrm{mg} / \mathrm{mL}$ in $\mathrm{CH}_{3} \mathrm{CN}$; 4-Cl and $\mathbf{5 - C l}=$ $2 \mathrm{mg} / \mathrm{mL}$ in dimethyl sulfoxide (DMSO); 6-ITh and 7-ITh= $10 \mathrm{mg} / \mathrm{mL}$ in DMSO. (2,2,6,6-Tetramethyl-piperidin-1-yl)oxyl (TEMPO) $(5 \mathrm{mg} / \mathrm{mL})$ was also added to 6-ITh and 7-ITh.

As for the mode of adding $\mathrm{H}_{2} \mathrm{O}$ to the reactions, four methods were evaluated.

Method 0: the target water was passed through a MP-1 resin, and the trapped fluoride was eluted using a solution containing $15 \mathrm{mg}$ of $\mathrm{K}_{222}$ in $1 \mathrm{~mL}$ of $\mathrm{CH}_{3} \mathrm{CN}$ and $80 \mu \mathrm{L}$ of $10 \% \mathrm{w} / v$ aqueous $\mathrm{K}_{2} \mathrm{CO}_{3}$. This mixture was azeotropically dried, and the residue was reconstituted with $600 \mu \mathrm{L}$ of the desired solvent. The precursors investigated were dissolved in the same anhydrous solvent, and multiple $(n>15)$ Automatic Discovery reactions were run in order to find the optimal conditions that maximize incorporation yield.

Method A: differs from Method 0 by the fact that varying percentages of $\mathrm{H}_{2} \mathrm{O}(5-50 \%)$ were added to the precursor solution. The mixtures obtained were utilized only if no precipitation occurred.

Method B: the precursor was prepared by dilution with the appropriate anhydrous solvent, whereas the labeling complex consisted of the usual solution of $\mathrm{K}_{222} / \mathrm{K}_{2} \mathrm{CO}_{3}$ in organic solvent together with varying quantities of irradiated target water directly added, leading to a final variable content of $\mathrm{H}_{2} \mathrm{O}$ (5$10 \%)$. Usual labeling optimizations were run.
Method C: differs from Method 0 by the fact that the complex eluted from the MP-1 cartridge was not azeotropically dried, therefore resulting in a labeling solution containing approximately $10 \%$ of $\mathrm{H}_{2} \mathrm{O}$, whereas the precursor was prepared in the traditional way.

Method D: $\mathrm{K}_{222} / \mathrm{K}_{2} \mathrm{CO}_{3}$ solution, irradiated target water (delivered as a solution premixed through a $<5 \mu \mathrm{L}$ Y-junction or a heated $7-\mu \mathrm{L}$ microreactor), and anhydrous precursor solution were continuously delivered in the heated microreactor. Custom automatic macros were written in order to handle the setup shown in Figure 4.

In every method, except $\mathrm{D}$, optimization runs were performed by varying temperature $\left(130-190^{\circ} \mathrm{C}\right)$ and reagent ratios $\left({ }^{18} \mathrm{~F} /\right.$ precursor from 1 to 10$)$, while the ${ }^{18} \mathrm{~F}$ flow rate varied from 5 to $20 \mu \mathrm{L} / \mathrm{min}$. Water percentage was varied by modifying the relative ratios of hydrous and anhydrous solutions. In Method D, only the best conditions in terms of temperature and maximum useful water content were employed without further optimization.

2.3. Labeling of Provisional Synthons in Hydrous Conditions $\left(8^{18} \mathrm{~F}, 9-{ }^{18} \mathrm{~F}, 10-{ }^{18} \mathrm{~F}\right)$. Precursor solutions were prepared in $\mathrm{CH}_{3} \mathrm{CN}$ for 8-OTs $(20 \mathrm{mg} / \mathrm{mL}), \mathbf{9 - C l}$, and $\mathbf{1 0 - C l}$ $(0.5 \mathrm{mg} / \mathrm{mL})$ and were charged into the respective loop, whereas the radiofluorination complex was eluted out of the anionexchange MP-1 cartridge using $1 \mathrm{~mL}$ of the usual $\mathrm{K}_{222} / \mathrm{K}_{2} \mathrm{CO}_{3}$ elution solution and charged into its storage loop without further processing (Method $C$ ). Optimized microfluidic conditions are as follows: $20 \mu \mathrm{L} / \mathrm{min}, 1: 1$ ratio with fluorinating complex at $130{ }^{\circ} \mathrm{C}$ for $\mathbf{8}^{\mathbf{1 8}} \mathbf{F}$ (93\% yield); $20 \mu \mathrm{L} / \mathrm{min}, 1: 1$ ratio with fluorinating complex at $30{ }^{\circ} \mathrm{C}$ for $\mathbf{9 -}{ }^{18} \mathbf{F}(91 \%$ yield $) ; 20 \mu \mathrm{L} / \mathrm{min}, 1: 1$ ratio with fluorinating complex at $100{ }^{\circ} \mathrm{C}$ for $\mathbf{1 0 -}{ }^{\mathbf{1 8}} \mathbf{F}$ (83\% yield).

\section{Results and Discussion}

3.1. Model Reactions Employed. The precursors tested in this work are shown in Figure 1 and have been chosen as models for aliphatic substitution (1-OTs, 2-OTs, and 3-OTs), aromatic substitution (4-Cl, 5-Cl), and aryliodonium salts (6-ITh, 7-ITh). The labeling of some of these molecules has been already reported in anhydrous conditions, both in vessel and in microfluidic conditions [7, 10, 7b].

The microfluidic apparatus used in the study allowed rapid optimization of radiolabeling conditions by employing the minimum quantity of reagents and radioactivity necessary [11]. The

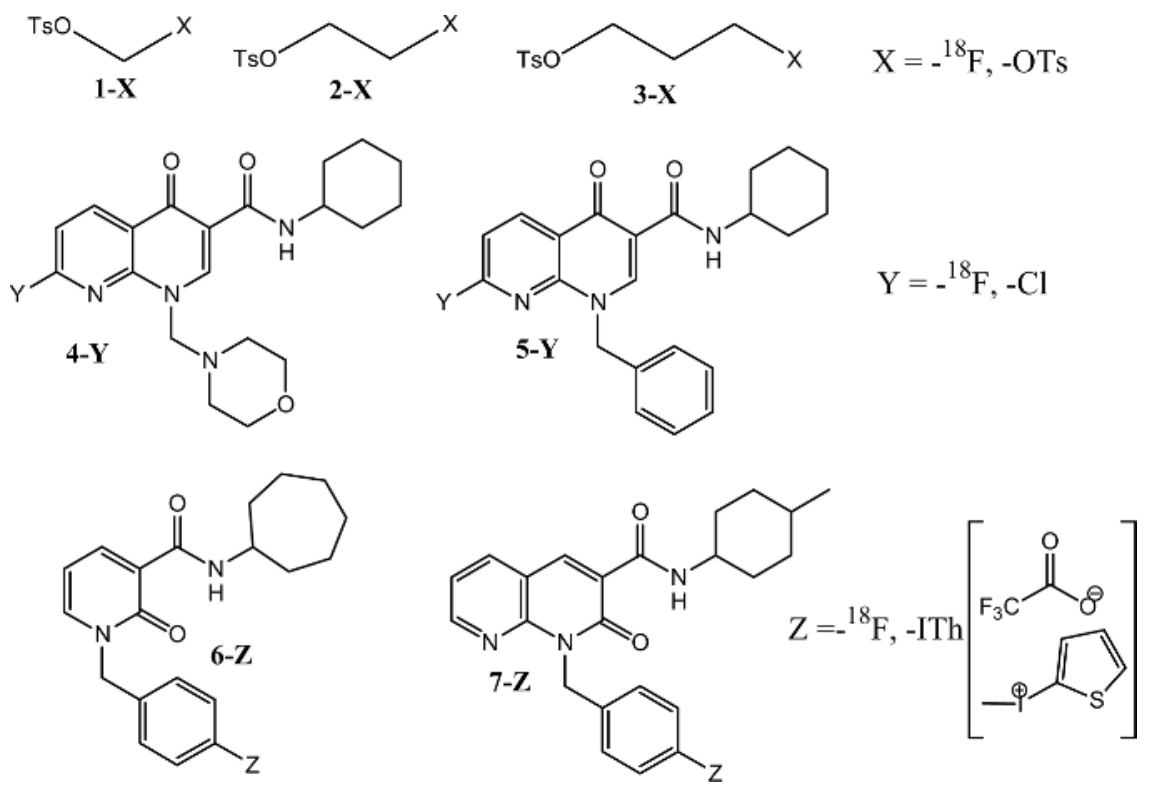

Figure 1. Structures of the model structures studied in this work 
Table 1. Experimental conditions for optimal yields of $\left[{ }^{18} \mathrm{~F}\right]$-fluoride incorporation using aliphatic precursors; methods: $0, \mathrm{~A}, \mathrm{~B}, \mathrm{C}(15.6 \mu \mathrm{L}$ reactor, $n=3$ unless stated otherwise)

\begin{tabular}{|c|c|c|c|c|c|c|c|}
\hline Precursor [solvent] & Precursor $(\mu \mathrm{L})$ & ${ }^{18} \mathrm{~F}$ complex $(\mu \mathrm{L})$ & $\begin{array}{l}\text { Overall flow } \\
\text { rate }(\mu \mathrm{L} / \mathrm{min})\end{array}$ & $T\left({ }^{\circ} \mathrm{C}\right)$ & $\begin{array}{c}\text { Incorporation } \\
\text { yield }(\%)\end{array}$ & Method & $\begin{array}{l}\mathrm{H}_{2} \mathrm{O} \text { in overal } \\
\text { mixture }(\%)\end{array}$ \\
\hline \multirow[t]{3}{*}{ 1-OTs $(20 \mathrm{mg} / \mathrm{mL})\left[\mathrm{CH}_{3} \mathrm{CN}\right]$} & 10 & 10 & 40 & 170 & $6 \pm 4$ & 0 & 0 \\
\hline & 20 & 20 & 40 & 170 & $47 \pm 7$ & $A$ & 4.5 \\
\hline & 20 & 20 & 30 & 170 & $63 \pm 5$ & $C$ & 3.7 \\
\hline \multirow[t]{4}{*}{ 2-OTs $(20 \mathrm{mg} / \mathrm{mL})\left[\mathrm{CH}_{3} \mathrm{CN}\right]$} & 10 & 10 & 40 & 170 & $71 \pm 8$ & 0 & 0 \\
\hline & 10 & 10 & 40 & 170 & $66 \pm 5$ & $A$ & 2.4 \\
\hline & 20 & 20 & 40 & 170 & $91 \pm 10$ & $B$ & 5.4 \\
\hline & 20 & 20 & 30 & 170 & $86 \pm 10$ & $C$ & 3.7 \\
\hline \multirow[t]{4}{*}{ 3-OTs $(20 \mathrm{mg} / \mathrm{mL})\left[\mathrm{CH}_{3} \mathrm{CN}\right]$} & 10 & 10 & 40 & 170 & $80 \pm 6$ & 0 & 0 \\
\hline & 10 & 10 & 40 & 170 & $83 \pm 3$ & $A$ & 2.4 \\
\hline & 20 & 20 & 40 & 170 & $80 \pm 4$ & $B$ & 5.4 \\
\hline & 30 & 30 & 30 & 170 & $58 \pm 5$ & $C$ & 3.7 \\
\hline
\end{tabular}

$\left[{ }^{18} \mathrm{~F}\right]$-fluoride incorporation yields were evaluated by radioHPLC, confirmed by radio-TLC, and averaged over a minimum of three runs. The maximum radiochemical yields achieved have been reported in relation to the corresponding precursor class and are reported in Tables 1-3.

3.2. Methods Description and Discussion. During the radiolabeling optimization of the aryliodonium salt 6-ITh precursor, it was noticed that the $\left[{ }^{18} \mathrm{~F}\right]$-fluoride incorporation yield was inconsistent between experiments (e.g., between 5\% and $40 \%$ yield). The cause was not initially investigated, until a fresh bottle of anhydrous DMSO was used (the first 5 days were run with the same DMSO bottle). Using this new bottle, the yield dropped again to the $5 \%$ level. It was hypothesized that uncontrolled hygroscopicity was the cause of the increasing radiochemical yield. To assess this, an additional $10 \%$ of $\mathrm{H}_{2} \mathrm{O}$ was added directly to the solution containing the precursor, and this resulted in a sudden increase in yield to $40 \%$ [7a]. This unexpected finding primed the interest of the authors toward the tolerance and, sometimes, the requirement of predetermined water content into the radiofluorination mixture when using microfluidic conditions [7b].

We chose to study several different model reactions employing aliphatic, aromatic, and aryliodonium precursors. In addition to that, we varied the method of addition of water to the reaction mixture and compared the results obtained with a typical procedure employing azeotropic distillation and stringent anhydrous conditions. Five different reaction methods were defined and named as Method 0, Method A, Method B, Method $C$, and Method D. For each method and each precursor, experimental runs have been used for optimizing temperature, residence time and reagent quantities, similar to what is reported in the literature [10].

Method 0 used traditional anhydrous conditions and was the benchmark for comparison of microfluidic findings.

Method $A$ aimed to investigate the effect of adding different quantities of water into the solution of the precursor to be labeled while using the same starting batch of azeotropically dried $\left[{ }^{18} \mathrm{~F}\right]$-complex. Up to four precursor solutions with varying percentages of $\mathrm{H}_{2} \mathrm{O}$ were prepared. Figure 2 reports a typical example of the effect of different water percentages in the precursor solution (shown for the radiolabeling of 3-OTs); the percent yield of labeled product inversely mirrors the unreacted fluoride. This hydrous method could not be used for compounds 4-Cl and 5-Cl because the addition of small percentages of water to their DMSO solution at room temperature caused instant precipitation that was not reversible by sonication or heating.

Method $B$ was conducted by preparing the labeling complex by mixing $\mathrm{K}_{222} / \mathrm{K}_{2} \mathrm{CO}_{3}$ in $\mathrm{CH}_{3} \mathrm{CN}$ with small volumes of irradiated target water, thus resulting in a starting complex containing variable amounts of $\mathrm{H}_{2} \mathrm{O}(5 \%$ to $10 \%)$. Each batch of radioactive solution with a pre-determined $\mathrm{H}_{2} \mathrm{O}$ percentage could be used to test the labeling of different precursors, even if they were dissolved in different solvents. An example of these experiments is reported in Figure 3, in which the same labeling solution was used to label 1-OTs, 3-OTs, and 5-Cl, thus further demonstrating the increased experimental breakthrough achievable with a microfluidic approach.

Method $C$ was used to test whether the radioactive complex eluted out of a MP-1 anion-exchange cartridge, containing $c a$. $10 \%$ of $\mathrm{H}_{2} \mathrm{O}$, could be used directly in the radiofluorination process without detrimental effects on the incorporation yield. This procedure represents the simplest operation achievable in any radiochemistry process and a successful result in this direction would lead to a reduction of the hardware and time required to perform a successful radiolabeling step. To assess this hypothesis, we also used the same eluted complex with a different precursor solution, thus allowing greater comparability of the obtained incorporation data together with a considerable reduction in experimental time. The results obtained with this method are reported in Tables 1-2.

Method $D$ is an important breakthrough in the radiofluorination field because it is an example of the online use of the reactants with the target water coming directly from the cyclotron. The three different reagents $\left(\mathrm{K}_{222} / \mathrm{K}_{2} \mathrm{CO}_{3}\right.$ solution, target water, precursor solution) are delivered into the heated

Table 2. Experimental conditions for optimal yields of $\left[{ }^{18} \mathrm{~F}\right]$-fluoride incorporation using aromatic and aryliodonium precursors; methods: $0, \mathrm{~A}, \mathrm{~B}, \mathrm{C}(15.6 \mu \mathrm{L}$ reactor, $n=3$ unless stated otherwise)

\begin{tabular}{|c|c|c|c|c|c|c|c|}
\hline Precursor [solvent] & Precursor $(\mu \mathrm{L})$ & ${ }^{18} \mathrm{~F}$ complex $(\mu \mathrm{L})$ & $\begin{array}{l}\text { Overall flow rate } \\
\qquad(\mu \mathrm{L} / \mathrm{min})\end{array}$ & $T\left({ }^{\circ} \mathrm{C}\right)$ & $\begin{array}{l}\text { Incorporation } \\
\text { yield }(\%)\end{array}$ & Method & $\begin{array}{c}\mathrm{H}_{2} \mathrm{O} \text { in overall } \\
\text { mixture }(\%)\end{array}$ \\
\hline \multirow[t]{2}{*}{ 4-Cl (2 mg/mL) [DMSO] } & 10 & 10 & 40 & 190 & $70 \pm 5$ & 0 & 0 \\
\hline & 10 & 50 & 60 & 190 & $54 \pm 3$ & $B$ & 1.8 \\
\hline \multirow{2}{*}{ 5-Cl $(2 \mathrm{mg} / \mathrm{mL})[\mathrm{DMSO}]$} & 15 & 60 & 50 & 190 & $61 \pm 6$ & $B$ & 2.1 \\
\hline & 20 & 80 & 50 & 180 & $60 \pm 4$ & $C$ & 1 \\
\hline \multirow[t]{2}{*}{ 6-ITh $(10 \mathrm{mg} / \mathrm{mL})$ [DMSO] } & 10 & 10 & 40 & 190 & $5 \pm 3$ & 0 & 0 \\
\hline & 10 & 10 & 30 & 190 & $40 \pm 7$ & $A$ & 5 \\
\hline \multirow[t]{3}{*}{ 7-ITh $(10 \mathrm{mg} / \mathrm{mL})$ [DMSO] } & 15 & 22.5 & 50 & 170 & $10 \pm 3$ & 0 & 0 \\
\hline & 15 & 22.5 & 50 & 190 & $40 \pm 5$ & $A$ & 5.5 \\
\hline & 20 & 20 & 10 & 190 & $56 \pm 4$ & $C$ & 5.4 \\
\hline
\end{tabular}


Table 3. Experimental conditions for optimal yields of $\left[{ }^{18} \mathrm{~F}\right]$-fluoride incorporation for selected compounds using Method $D(15.6 \mu \mathrm{L}$ reactor, $n=3$ unless stated otherwise)

\begin{tabular}{|c|c|c|c|c|c|c|c|}
\hline Precursor [solvent] & ${ }^{18} \mathrm{~F}$ water $(\mu \mathrm{L})$ & $\mathrm{K}_{222} / \mathrm{K}_{2} \mathrm{CO}_{3}(\mu \mathrm{L})$ & Precursor $(\mu \mathrm{L})$ & $\begin{array}{l}\text { Overall flow } \\
\text { rate }(\mu \mathrm{L} / \mathrm{min})\end{array}$ & $T\left({ }^{\circ} \mathrm{C}\right)$ & $\begin{array}{l}\text { Incorporation } \\
\text { yield }(\%)\end{array}$ & $\begin{array}{l}\mathrm{H}_{2} \mathrm{O} \text { in overall } \\
\text { mixture }(\%)\end{array}$ \\
\hline 1-OTs $(20 \mathrm{mg} / \mathrm{mL})\left[\mathrm{CH}_{3} \mathrm{CN}\right]$ & 10 & $100\left[\mathrm{CH}_{3} \mathrm{CN}\right]$ & 220 & 165 & 170 & $51 \pm 4$ & 6 \\
\hline 2-OTs $(20 \mathrm{mg} / \mathrm{mL})\left[\mathrm{CH}_{3} \mathrm{CN}\right]$ & 10 & 100 & 220 & 60 & 170 & $70 \pm 5$ & 5.3 \\
\hline 5-Cl $(2 \mathrm{mg} / \mathrm{mL})[\mathrm{DMSO}]$ & 10 & 100 & 495 & 83 & 170 & $34 *$ & 4 \\
\hline
\end{tabular}

microreactor at set ratios and rates in order to directly obtain the proper environment inside the system that would allow an acceptable incorporation radiochemical yield to be obtained. A successful outcome of this procedure would synthesize the $\left[{ }^{18} \mathrm{~F}\right]$-radiotracers without any pretreatment or drying of the $\mathrm{K}_{222} / \mathrm{K}^{18} \mathrm{~F}$ complex, which is totally unprecedented in this field. To evaluate this hypothesis, the optimal conditions in terms of temperature, precursor concentration, and maximum water content were used to process larger boluses (total final volume $>400 \mu \mathrm{L}$ ) of reagents, thus mimicking a semi-continuous production, currently limited by the target water volume. The overall flow rate was set by imposing a minimum speed of $5 \mu \mathrm{L} / \mathrm{min}$ to the target water containing the $\left[{ }^{18} \mathrm{~F}\right]$-fluoride and by adjusting the other reagents' flows in order to set the $\mathrm{H}_{2} \mathrm{O}$ percentage in the bolus mixture to the desired level. The employment of these adjusted flow parameters did not allow the same residence time to be perfectly reproduced as tested in the previous methods due to the use of fixed internal volume microreactors. However, previous studies have demonstrated that, in most cases, small variations in residence time have a much smaller effect on $\left[{ }^{18} \mathrm{~F}\right]$-fluoride incorporation yield, compared to temperature or precursor concentration [12].

Even if the data collected were sufficient in terms of yields (Table 3), important issues had to be solved due to undesired blockages and breakages experienced in the microreactor system. Blocking issues could be mitigated when $\mathrm{CH}_{3} \mathrm{CN}$ was used as a solvent, by preheating some components before merging them together. An improved setup was established by delivering $\mathrm{K}_{222} / \mathrm{K}_{2} \mathrm{CO}_{3}$ solution and target water into a heated, short $(7 \mu \mathrm{L})$ microreactor, before delivering this mixture into the main microreactor together with the precursor solution, as shown in Figure 4.

However, the use of multiple solvents, such as $\mathrm{CH}_{3} \mathrm{CN}$ for the $\mathrm{K}_{222} / \mathrm{K}_{2} \mathrm{CO}_{3}$ complex, DMSO for the precursor, and target water, also affected system performance when using this preheating approach and caused frequent breakages. In fact, when DMSO was needed as a precursor solvent, it was only possible to obtain a process free of problems in one experiment $(\mathbf{5 - C l}$, Table 3) using Method D. The use of microreactors featuring

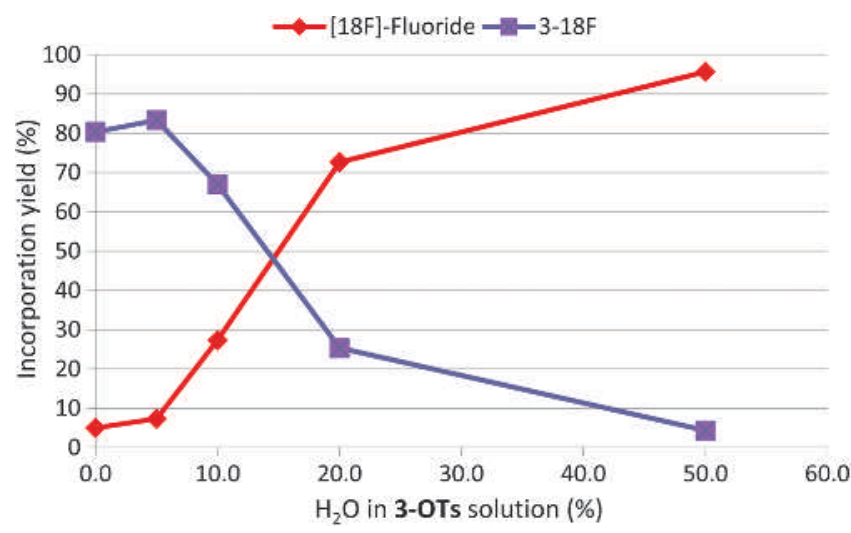

Figure 2. Maximum incorporation yield versus $\% \mathrm{H}_{2} \mathrm{O}$ (Method $\mathrm{A}$, single trial) present in 3-OTs precursor solution (conditions: $170^{\circ} \mathrm{C}$, $10+10 \mu \mathrm{L}$ bolus, overall flow rate $40 \mu \mathrm{L} / \mathrm{min}$ )

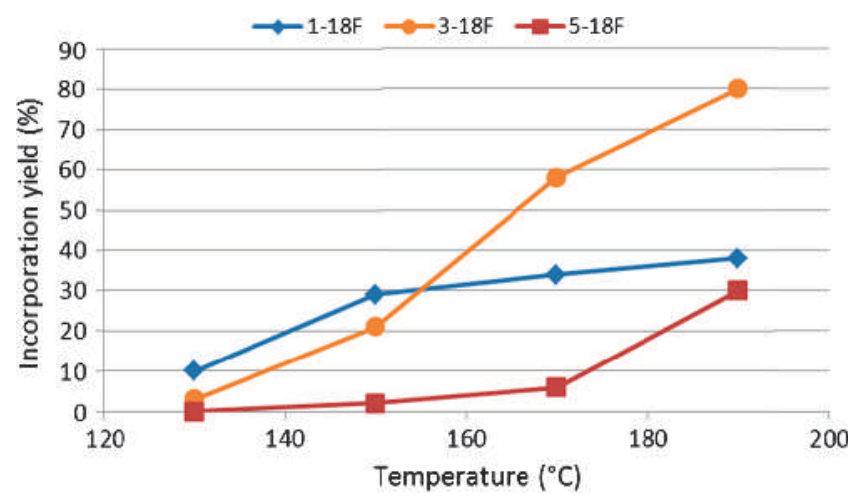

Figure 3. Incorporation yields versus` temperature (Method B, single trials) using the same labeling complex containing $11 \%$ of $\mathrm{H}_{2} \mathrm{O}$ (in $\mathrm{CH}_{3} \mathrm{CN}$ ), used on different precursors: 1-OTs, 3-OTs, and 5-Cl (in DMSO) (conditions: $20+20 \mu \mathrm{L}$ bolus, overall flow rate $40 \mu \mathrm{L} / \mathrm{min}$ )

thicker walls to perform this procedure is currently being investigated.

3.3. Discussion of Results on Model Structures. The results reported in Tables 1-3 confirmed the hypothesis that, at least when using a highly productive microfluidic approach, the presence of single digit percentages of water in the overall reaction mixture is well tolerated, yielding radioactive incorporation yields that are similar to the results obtained in anhydrous conditions. It is generally true in the case of the model aliphatic systems, in which the radiochemical incorporation yield was basically unmodified $\left(\mathbf{3 -}^{\mathbf{1 8}} \mathbf{F}\right.$ from $80 \%$ to $83 \%$ with $\left.2.5 \% \mathrm{H}_{2} \mathrm{O}\right)$, increased $\left(\mathbf{2 -}^{\mathbf{1 8}} \mathbf{F}\right.$ from $71 \%$ to $91 \%$ with $\left.5.4 \% \mathrm{H}_{2} \mathrm{O}\right)$ or substantially increased $\left(\mathbf{1 -}^{\mathbf{1 8}} \mathbf{F}\right.$ from $6 \%$ to $63 \%$ with $\left.3.7 \% \mathrm{H}_{2} \mathrm{O}\right)$. Due to the striking effect of this last case, which has already been reported in microfluidic [7b] and in vessel systems [7b], further investigations are required to understand the chemical reasons underlying this phenomenon. A possible explanation could be given by the softer electrophilic nature of the carbon atom compared to the sulfur atom in the ditosylate precursor, with a hydrated fluoride being a softer nucleophile than an anhydrous one [13].

In the case of aromatic precursors, a comparison of incorporation yields between hydrous and anhydrous conditions generally shows a $20 \%$ decrease in the presence of $2 \% \mathrm{H}_{2} \mathrm{O}\left(\mathbf{4 -}^{\mathbf{1 8}} \mathbf{F}\right.$ from $70 \%$ to $54 \%$ with $1.8 \% \mathrm{H}_{2} \mathrm{O} ; \mathbf{5 -}^{\mathbf{1 8}} \mathbf{F}$ from $88 \%$ to $61 \%$ with $2.1 \% \mathrm{H}_{2} \mathrm{O}$ ). This evidence allows the researcher to make a trade-off choice depending on the experimental needs. This trade-off might lean toward the use of hydrous conditions when a simpler setup and shorter procedure times are employed as

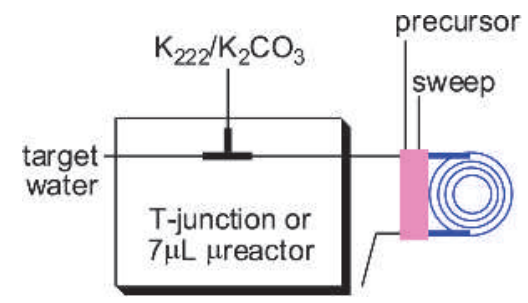

Figure 4. Plumbing of microreactor for Method D 


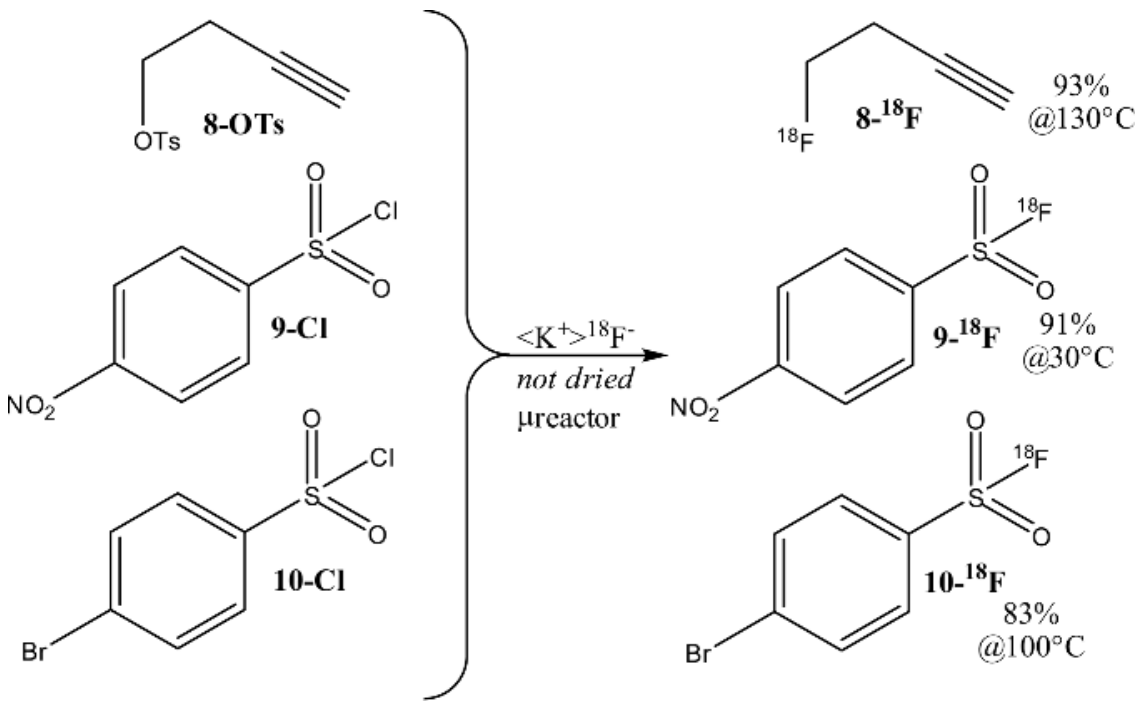

Figure 5. Structures of the three provisional synthons labeled in hydrous conditions and their best incorporation yield

parameters which are of paramount importance. Conversely, anhydrous conditions might be preferred when the radioactivity recovery is a priority, as in the case of routine synthesis of ${ }^{18} \mathrm{~F}$-fluorinated radiotracers at dedicated production sites.

Nevertheless, we found that the presence of water is required to obtain favorable radiochemical incorporation yields for the aryliodonium salts tested in this study. In fact, yields increased dramatically in the presence of $5 \% \mathrm{H}_{2} \mathrm{O}$ in the overall reaction bolus $\left(\mathbf{6}^{18} \mathbf{F}\right.$ from $5 \%$ to $40 \%, 7^{78} \mathbf{F}$ from $10 \%$ to $\left.40 \%\right)$. A further study on 6-ITh was conducted by reacting the anhydrous DMSO fluorinating complex a) with the sole anhydrous precursor solution, b) with only TEMPO added (as radical scavenger) [14], or c) with TEMPO and $10 \% \mathrm{H}_{2} \mathrm{O}$ added. In these experimental runs $\left(T=190{ }^{\circ} \mathrm{C}\right.$, overall flow rate $40 \mu \mathrm{L} /$ min, $15+15 \mu \mathrm{L}$ bolus), the incorporation yields for the three conditions were $6 \%, 10 \%$, and $40 \%$, respectively. This fact demonstrated that, with this precursor, the addition of water contributed significantly more to radiochemical incorporation increase than the use of TEMPO. The reason for this effect might be ascribed to the interaction of the different chemical environments with the activated complex, as suggested in recent studies [14], using other conditions, although further experiments are needed to fully explain this result. Recent work by Chun [15] confirmed this fact and allowed $>50 \%$ incorporation yields to be obtained on other model aryliodonium salts in the presence of $35 \% \mathrm{H}_{2} \mathrm{O}$.
Our data suggest that the method of $\mathrm{H}_{2} \mathrm{O}$ addition is not fundamental to obtain a successful radiofluorination process. We therefore envisage that the use of Method $C$ would be very valuable because it is readily achievable in any microfluidic hardware without any modifications to the preparation of the synthetic system. On the other hand, Method $D$ would require a slight modification to the hardware but, if thoroughly optimized, it could represent an important improvement to the radiofluorination process. The method would even be utilized in routine synthesis at production sites, due to its decreased hardware and operational requirements.

3.4. Change of Methodological Approach. In our intention to change the approach to radiolabeling of the new substrates using a simpler and faster hydrous method, we tested the use of Method $C$ for optimizing the production of novel $\left[{ }^{18} \mathrm{~F}\right]$-fluorinated structures (Figure 5). $\left[{ }^{18} \mathrm{~F}\right] 4$-fluoro-1-butyne $\left(\mathbf{8}^{\mathbf{1 8}} \mathbf{F}\right)$ is a synthon with great interest for its subsequent use in clickchemistry-mediated labeling of macromolecules; we therefore studied its production from the corresponding tosylate directly using Method $C$ in the same microfluidic environment previously shown. Reaction tests were conducted at increasing temperatures, keeping the ratio $(1: 1)$ constant between both the precursor and radioactive complex and the corresponding flows ( $20 \mu \mathrm{L} / \mathrm{min}$ ). We were delighted to find that the best incorporation yield obtainable at $130{ }^{\circ} \mathrm{C}$ in hydrous conditions $(93 \pm 5 \%)$ was comparable to the one attained using the anhydrous

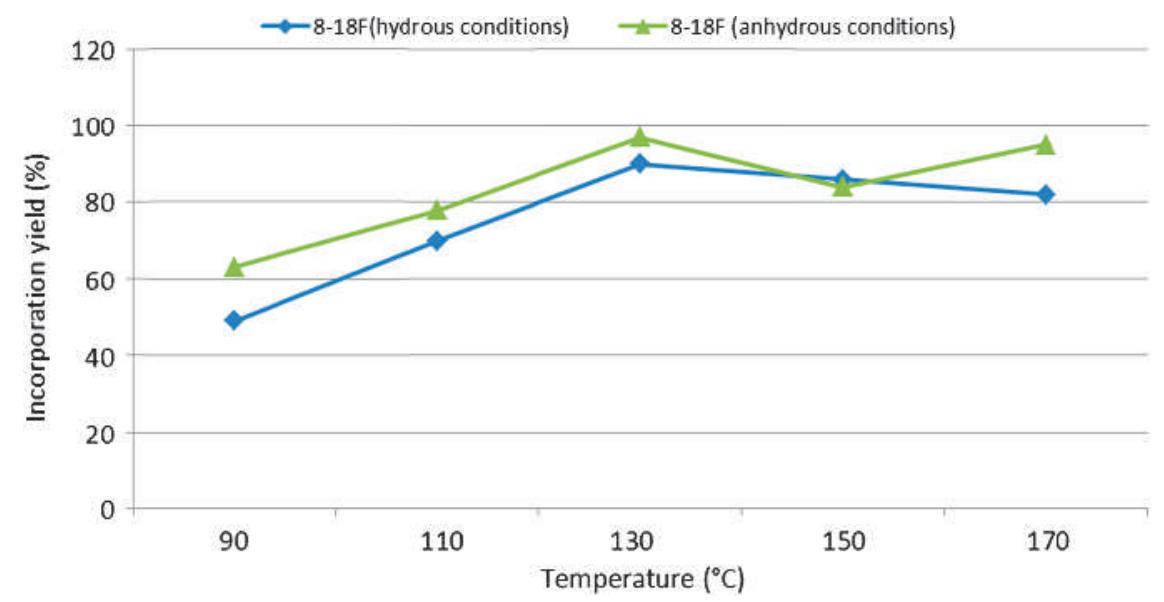

Figure 6. Comparison between the incorporation yield of hydrous and anhydrous conditions versus temperature (Method C, single trial) using the same 8-OTs solution $\left(20 \mathrm{mg} / \mathrm{mL}\right.$ in $\left.\mathrm{CH}_{3} \mathrm{CN}\right)$ 
a

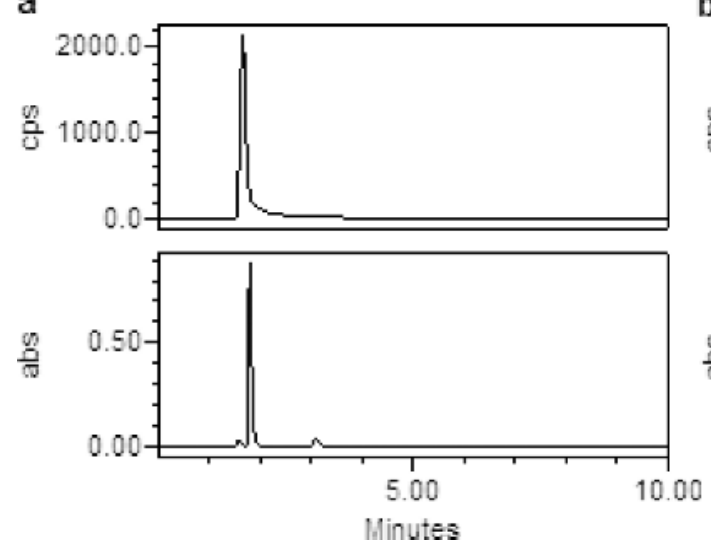

b

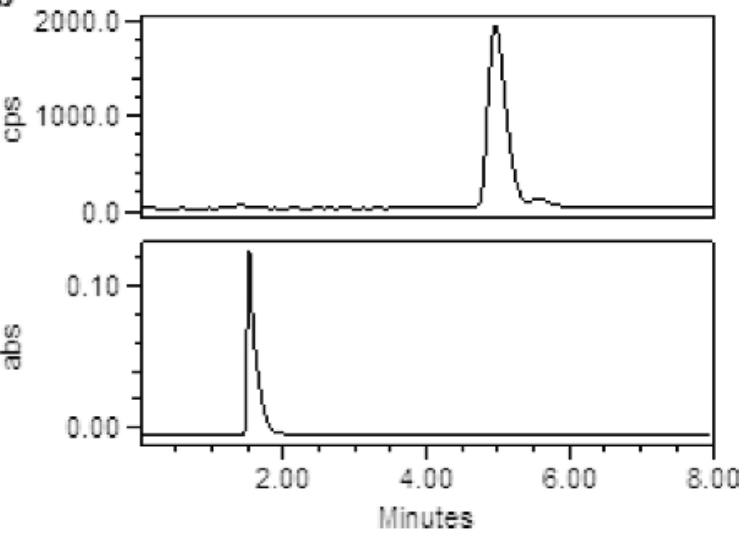

Figure 7. Crude radio-HPLC chromatograms of $\mathbf{9 -}_{-}^{\mathbf{1 8}} \mathbf{F}$ performed with $0.5 \mathrm{mg} / \mathrm{mL}$ of $\mathbf{9 - C l}$ at $30{ }^{\circ} \mathrm{C}$ and a flow rate of $20 \mu \mathrm{L} / \mathrm{min}$ in (a) anhydrous conditions and (b) hydrous conditions $\left(5 \% \mathrm{H}_{2} \mathrm{O}\right)$. Top trace is radioactivity profile, bottom trace is UV absorption. 9- ${ }^{18} \mathbf{F}$ has a $\mathrm{Rt}=5 \mathrm{~min}$

conditions $(95 \pm 4 \%)$ that we applied in a separate set of experiments, as shown in Figure 6.

Encouraged by the positive results on the butyne substrate, we tested Method $C$ on the radiofluorination of another potential class of synthons, model aromatic $\left[{ }^{18} \mathrm{~F}\right]$-benzenesulfonylfluorides. We therefore assessed the radiolabeling of 4-nitro- $(\mathbf{9 - C l})$ and 4-bromobenzenesulfonyl chlorides (10-CI). In both examples, we obtained maximum isolated yields of $>80 \%$. The case of 9-Cl was particularly noteworthy since radiolabeling conducted using anhydrous conditions demonstrated that the fluorination reaction can occur only at low temperatures and with a higher concentration of precursor $(>2 \mathrm{mg} / \mathrm{mL})$, probably due to competing decomposition of the acid [16]. Instead, in the presence of the hydrous complex $\left(5 \% \mathrm{H}_{2} \mathrm{O}\right)$, a low concentration $(0.5 \mathrm{mg} / \mathrm{mL})$ of $\mathbf{9 - C l}$ was sufficient to obtain $91 \%$ radiochemical incorporation yield at $30{ }^{\circ} \mathrm{C}$ at a flow rate of $20 \mu \mathrm{L} / \mathrm{min}$ for both precursor and fluorination complex. A comparison of HPLC chromatograms for this reaction under hydrous and anhydrous conditions is presented in Figure 7. Interestingly, the incorporation yield of $9-{ }^{18} \mathbf{F}$ decreased dramatically to $4 \%$ at $100{ }^{\circ} \mathrm{C}$ under the same conditions. To circumvent this, higher flow rates $(50-125 \mu \mathrm{L} / \mathrm{min}$ for each stream) were employed, and it was discovered that a $32 \%$ radiochemical incorporation yield could still be obtained at $100{ }^{\circ} \mathrm{C}$ using a flow rate of $100 \mu \mathrm{L} / \mathrm{min}$ for each reagent.

The brominated 10-Cl was able to be radiolabeled in the same incorporation yield at $30{ }^{\circ} \mathrm{C}(81 \%)$ under anhydrous and hydrous conditions $\left(5 \% \mathrm{H}_{2} \mathrm{O}\right)$. In contrast, the $\left[{ }^{18} \mathrm{~F}\right]$-radiofluorination yield at $100{ }^{\circ} \mathrm{C}$ was $83 \%$ under hydrous conditions, while only $19 \%$ with anhydrous conditions [15]. The yields of $\mathbf{1 0}-{ }^{18} \mathbf{F}$ started to decrease at $160{ }^{\circ} \mathrm{C}$ under hydrous conditions, with a $48 \%$ yield obtained at $180{ }^{\circ} \mathrm{C}$, compared to no product being formed above $120{ }^{\circ} \mathrm{C}$ using anhydrous conditions [15].

\section{Conclusion}

In this work, we have shown that radiofluorinations performed in a microfluidic environment can tolerate single-digit percentages of water added in different modalities, at least on the selected set of precursors and conditions tested. In comparison to anhydrous conditions, the incorporation yield is generally reduced when using aromatic substrates, is comparable when employing aliphatic tosylates, and is improved in the case of aryliodonium precursors, in agreement with recently reported data [15]. These results could induce a methodological change in the operation of initial microfluidic radiofluorination optimizations or, more likely, simplify the procedure for setting up the reactions (e.g., use of solvents with a lower grade of anhydricity, faster azeotropic distillations).
We evaluated the methodological change by directly using hydrous radiolabeling conditions on some novel precursor structures, obtaining satisfactory radiochemical yields similar to $\left(\mathbf{8}^{-18} \mathbf{F}\right)$ or even greater $\left(\mathbf{9 -}^{\mathbf{1 8}} \mathbf{F}\right)$ than the corresponding ones obtained in an anhydrous environment.

The reasons for this noticeable tolerance have not yet been studied, and it is likely to be precursor-dependent, even though the use of increased surface-to-volume ratio, the employment of high temperatures and the totally closed environment, typical of a microfluidic environment, may also play an important role in this regard. Further investigations into the underlying basis of this phenomenon are currently underway.

Acknowledgment. The authors would like to thank students from University of Leuven (BG), Maude De Cooman, and Anne Calsius for their collaboration in some of the reported experiments.

\section{References}

1. Lapi, S. E.; Welch M. J. Nucl. Med. Biol. 2012, 39, 601-608.

2. Cai, L.; Lu, S.; Pike, V. Eur. J. Org. Chem. 2008, 6, 2853-2873.

3. Kim, H. W.; Jeong, J. M.; Lee, Y. S.; Chi, D. Y.; Chung, K. H.; Lee, D. S.; Chung, J. K.; Lee M. C. Appl. Radiat. Isot. 2004, 61, 1241-1246.

4. Kim, D. W.; Jeong, H.-J.; Lim, S. T.; Sohn, M.-H.; Katzenellenbogen, J. A.; Chi, D. Y. J. Org. Chem. 2008, 73, 957-962.

5. (a) Aerts, J.; Voccia, S.; Lemaire, C.; Giacomelli, F.; Goblet, D.; Thonon, D. Plenevaux, A.; Warnock, G.; Luxen, A. Tetra. Lett. 2010, 51, 64-66; (b) Lemaire, C F.; Aerts, J. J.; Voccia, S.; Libert, L. C.; Mercier, F.; Goblet, D.; Plenevaux, A. R.; Luxen, A. J. Angewandte Chemie. 2010, 49, 3161-3164; (c) Voccia, S.; Aerts, J.; Lemaire, C.; Luxen, A.; Morelle, J.-L.; Philippart, G. WO 2008/128306, 2008.

6. (a) Hamacher, K.; Coenen, H. H. Appl. Radiat. Isot. 2006, 64, 989-994; (b) Saiki, H.; Iwata, R.; Nakanishi, H.; Wong, R.; Ishikawa, Y.; Furumoto, S.; Yamahara, R.; Sakamoto, K.; Ozeki, E. Appl. Radiat. Isot. 2010, 68, 1703-1708; (c) Wong, R.; Iwata, R.; Saiki, H.; Furumoto, S.; Ishikawa, Y.; Ozeki, E. Appl Radiat Isot, 2012, 70, 193-199.

7. (a) Telu, S.; Chun, J.; Simeon, H. F. G.; Lu, S.; Pike, V. W. Org. Biomol. Chem. 2011, 9, 6629-6638; (b) Neal, T. R.; Apana, S.; Berridge, M. S. J. Labelled Compd. Radiopharm. 2005, 48, 557-568; (c) Arima, V.; Pascali, G.; Lade, O.; Kretschmer, H. R.; Bernsdorf, I.; Hammond, V.; Watts, P.; De Leonardis, F; Tarn, M. D.; Pamme, N. Lab. Chip. 2013, 13, 2328-2336; (d) Lang, L.; Eckelman, W. C. Appl. Radiat. Isot. 1994, 45, 1155-1163.

8. (a) Pascali, G.; Pitzianti, S.; Del Carlo, S.; Saccomanni, G.; Manera, M.; Macchia, M.; Salvadori, P. A. J. Labelled Compd. Radiopharm. 2011, S502; (b) Pascali, G.; Del Carlo, S.; Saccomanni, G.; Manera, C.; Macchia, M.; Salvadori, P. J. Nucl. Med. Meeting Abstracts 2012, 53, 578.

9. Watts, P.; Pascali, G.; Salvadori, P. A. J. Flow. Chem. 2012, 2, 37-42.

10. Pascali, G.; Kiesewetter, D. O.; Salvadori, P. A.; Eckelman, W. C. J. Labelled Compd. Radiopharm. 2004, 47, 373-383.

11. Pascali, G.; Mazzone, G.; Saccomanni, G.; Manera, C.; Salvadori, P. A. Nucl. Med. Biol. 2010, 37, 547-555.

12. (a) Dahl, K.; Schou, M.; Halldin, C. J. Labelled Compd. Radiopharm 2012, 55, 455-459; (b) Ungersboeck, J.; Philippe, C.; Mien, L. K.; Haeusler, D.; Shanab, K.; Lanzenberger, R.; Spreitzer, H.; Keppler, B. K.; Dudczak, R.; Kletter, K.; Mitterhauser, M.; Wadsak, W. Nucl. Med. Biol. 2011, 38, 427-434.

13. Pearson, R.G. J. Am. Chem. Soc. 1963, 85, 3533-3539.

14. Yusubov, M. S.; Svitich, D. Y.; Larkina, M. S.; Zhdankin, V. V. ARKIVOC. 2013, 364-395.

15. Chun, J.-H.; Pike, V. W. Eur. J. Org. Chem. 2012, 24, 4541-4547.

16. Matesic, L.; Wyatt, N. A.; Fraser, B. H.; Roberts, M. P.; Pham, T. Q.; Greguric, I. J. Org. Chem. 2013, 78, 11262-11270. 